\title{
TEACHING POLITENESS OF USING SLANG IN SPEAKING: ANALYSIS OF CONVERSATIONS IN TUESDAYS WITH MORRIE
}

\author{
Sovia Rahmaniah \\ Fakultas Tarbiyah dan Keguruan, Program Studi Tadris Bahasa Inggris \\ Universitas Islam Negeri Antasari Banjarmasin \\ Email: soviarahmaniah@uin-antasari.ac.id
}

\begin{abstract}
Slang language is commonly used in American society in their daily life communication. However, teachers are still hesitant to teach slang in their speaking class, because slang language is assumed as impolite language. Most of the teachers don't realize that even slang language can be used in polite conversation. This paper is intended to show some analysis on some conversations in the movie entitle 'Tuesdays with Morrie' which are assumed as the representation of social language for American. The focus of the analysis is the use of slang in polite conversations. The analysis will be based on the identification of a communicative event along with three dimensions called field, tenor, and mode. The significance of the study is to clarify teachers' understanding toward slang language that can be assumed as a politeness, so the teachers will not hesitate to teach slang language to their students in speaking class. Furthermore, through this analysis, the students will know why, when, where, and how to use slang politely in their daily life conversation.
\end{abstract}

Keywords: Politeness, slang, Tuesdays with Morrie, teaching slang, teaching using movie analysis.

\section{INTRODUCTION}

Most of the teachers are hesitate to teach Slang language in their classes because some teachers believe that Slang language is not appropriate to be taught in the class. Slang has been known in Indonesia as a language used by young people. In America, Slang is used as part of their culture. It plays a significant part of American communication in movies, television, radio, newspapers, music, magazines and informal conversation. American slang shows the diversity in culture of American. Only by analyzing someone in using slang, the identity of that person can be revealed. There are many types of Slang language, and certain types of Slangs are used by certain types of groups. Understanding American slang can make us aware of culture differences in American communication and how getting closer to them by using the language the use as their in-group identity.
Research questions:

1. How can slang be used in polite conversation?

2. How the use of slang in polite conversation can contribute to teaching?

The purpose of this research is to find American slang that usually used in a polite conversation as seen in Tuesdays with Morrie and to convince the teachers that teaching American slang in the classroom is appropriate. This research is hopefully can provide teachers a new believe about teaching slang in their classroom, and will contribute to the appropriate American slang which teachers can include in the teaching materials. Moreover, it can give the students the understanding towards the use of American slang in polite conversation.

\section{A. Politeness}

The concept of politeness is important in communication because being 
polite allows individual to minimize the misunderstanding between speakers when they interact (Okabe, 1990). There are some ways to identify an existence of politeness in conversation. Janny and Arndt (1992) suggest that tact and social politeness are two types of politeness. Tact refers to interpersonal strategies for maintaining face, and social politeness refers to the rules that are used for smoothly organized interaction. Stockwell (2007) states the idea of politeness model which proposed by Brown and Levinson (1987, in Stockwell, 2007) which is determined by the notion of face. When the speaker is dealing with notion of face of politeness, he or she has decided the role that he/she wants to show to the world. Ting-Toomey (1994) defines face as a self-respect that is claimed by the speaker when he or she has interaction through communication.

Positive and negative politeness are the politeness strategies based on the notion of face. You use negative politeness if you want to do your action without obstacle, but you use positive politeness if you want to be identified as the part of the community you are talking to. Alternatively speaking, positive face is a person's need to be accepted and liked by others and the desire to feel that s/he shares certain common ground with the social group. Negative face, on the other hand, is the desire not to be imposed upon and to have the right to independence. Positive politeness orients to preserving the positive face of other people. It is an expression of solidarity with an intention to "emphasize that both speakers want the same thing, and that they have a common goal" (Yule, 1996). Alternatively, negative politeness is doing face saving acts oriented to other's negative face. It is an expression of minimal interference which tends to "emphasize the importance of the other's time or concerns, and even include an apology for the imposition or interruption" (Yule,1996).
Huang (2008) defines politeness as a social phenomenon to achieve good interpersonal relationships and a norm imposed by social conventions. The characteristic of politeness is it is instrumental, phenomenal and normative by nature. The standard of politeness are various across culture. In America, Americans prefer to emphasize intimacy based on equality when they are polite, they do not make distance when they are polite (Ogawa \& Gudykunst, 2000).

According to Leech (1983), to be considered as politeness, the speaker must consider these six maxims of politeness which related to its pragmatics' principles:

1. Tact Maxim

It is dealing with the scale of politeness which means what is polite for the speaker also has the same effect to the hearer (minimize the cost to other; maximize the benefit to other).

2. Generosity maxim

Offering and inviting (minimize benefit to self, maximize cost to self).

3. Approbation maxim

Minimize dispraise of other, maximize praise to other

4. Modesty maxim

Minimize dispraise of self, maximize dispraise of self.

5. Agreement maxim

Minimize disagreement between self and other, maximize agreement between self and other.

6. Sympathy maxim

Minimize antipathy between self and other, maximize sympathy between self and other. 
Some aspects of politeness can be the consideration to identify politeness criteria. There are some aspects of politeness which is proposed by Huang (2008): Politeness in greeting each other and saying farewell, politeness for addressing terms, politeness as a way to praise others, and politeness as a way to express thanks.

\section{B. Slang Language}

Slang is traditionally considered as a vulgar, offensive, and profane form of language with a strong color of irreverence and yet vitality in a society. Many sociolinguists have observed that slang can be an indicator of rebellious feelings or intentional detachment of speakers from particular mainstream values (Finegan, 2004). It is generally labeled as a linguistic taboo which should not be appearing in most formal social occasions. However, slang is a subset of a language used by one particular group. If the slang is used by American, it is called American slang. If it is used by African-American it is called African-American Slang. There are many types of slang around the world. The names are derived from the majority people invent and use it. It consists of words and expressions which often cannot be found in the standard dictionary or have different meaning with what is written in the standard dictionary.

O'Grady and Archibald (2004) describe slang as an informal register in languages. Register means variety of language which identify a communicative event along three dimensions. They are field, tenor, and mode (Stockwell, 2007). Field is the setting and purpose of interaction; tenor means the speaker and hearer relationship; and mode means medium of communications. Since, slang can be said as a register, it also has those three dimensions.

Although some people regard slang as a low and undesirable or nonstandard form of language, it keeps being popular register of language especially for adolescents and young adults or even old men. Slang is the language that a lot of people speak in everyday life. Hayakawa (1941) describes that slang is like the poetry of everyday life. Slang is used by all kinds of groups of people who share the same situations or interests. It is in line with Finegan (2004) who stated that slang is not only used by young people but also all members of a speech community in various informal situations.

People usually use slang to mark their in group identity. Also, the use of slang is intended to set the conversation difficult for ordinary people outside the group to understand the intended meaning. Anderson and Trudgill (1990) argued that slang has the power to make someone's speech lively, passionate and interesting because it creates humor, shows personality, simplifies speech and functions as a code to confuse people outside the group. Another power of slang is that it can make someone's relationship becomes closer. It is because slang can act as in-group identity. Slang reflects the experience, beliefs and values of its speaker which is useful to be employed in sharing common experiences. However, when the time goes by, slang can be out of style or become standardized, so the register that used to be slang can be no longer considered as slang (Zhou, 2005).

Even if slang has that strong power, someone' must still be careful when using slang. Mazer and Hunt (2008) propose two types of slang expression: positive slang and negative slang. Slang can be positive or negative in valence depending upon its use in communication encounters. Positive slang refers to informal language that a speaker may utilize to signal identification with the listener, establish or reinforce 
social identity, or as a rhetorical device to improve the feeling of solidarity. Negative slang refers to informal language - such as commonly used verbal obscenities - that listeners may perceive as offensive. Verbal obscenities (or profanity), by their very nature, comprise the bulk of what sociolinguists characterize as negative slang (Mazer, 2006; Rothwell,1971). Rothwell (1971) argues that the speaker use negative slang to attract attention using verbal obscenity including indecent words and phrases. As the result, positive slang can produce positive attitude from the listeners, and negative slang can produce negative attitude from the listeners. Consequently, as a speaker we should consider that the slang we used is positive slang.

Homuth and Piippo (2011) give the characteristics of slang which can be as the identification of the existence of slang in a conversation. Moreover, Homuth and Piippo (2011) state that if a word or phrases satisfied at least two of these characteristics, the word or phrase can be considered as slang:

1. It can reduce the level of formality.

2. It demonstrates in group familiarity. It is used when the speaker uses slang to create in-group status.

3. For people with high social status, slang is considered as taboo term.

4. It can be used for euphemism because it can replace a word that would cause discomfort to the speaker if he or she used the word instead.

Slang usually overlap with the understanding of idiom. Burke (1998) defines slang as nonstandard vocabulary of a given culture or subculture as the result of making up words. An idiom is usually a phrase that is commonly understood as a different literal meaning. In other words, slang is typically a nonstandard word, not a phrase as is an idiom even if sometimes slang is a phrase. However, the obvious difference is on its literal meaning. Slang words may or may not have alternative literal meanings, but idiom always have alternative literal meaning.

\section{METHODOLOGY}

\section{a. Research Design}

The research study belongs to a descriptive qualitative research design. The researcher will give the description about the slang that is used in polite conversation. The pattern of using slang will be described along with how they used it. The description of the slang that used in the conversation will be based on the identification of communicative event along with the three dimensions. Those three dimensions are field, tenor, and mode.

\section{b. Subjects}

The subject of this research is American at the age around 30 to 60 . They are the characters in the movie "Tuesdays with Morrie". The characters in Tuesdays with Morrie are educated people. The main characters in this movie are Morrie Schwartz and Mitch Albom. Morrie Schwatz was a professor and Mitch Albom was a sport commentator. Most of the conversation was happening between those two characters. Because of their educational background and their job, so it is assumed that they have understood the concept of politeness and known how to be polite to each other The other conversations from different characters was also included as long as they met the limitation of the study.

\section{c. Limitation of the Study}

The use of slang in polite conversations is the object of this research. So, the researcher only focused on slang 
which is used in polite conversation. The slang that is involved in narrations and impolite conversation cannot be included in this research.

\section{d. Instruments}

The researcher use a movie entitled Tuesdays with Morrie directed by Mick Jackson. The story was written by Mitch Albom, and most of the dialogs in the movie are almost the same as in the novel. This movie is based on true story, so it's assumed that the conversations of this movie will be closely related to real life conversation.

\section{e. Data Collection Procedure}

The data of this study comes from the polite conversations in Tuesdays with Morrie. The researcher watches the movie and give the attention to the polite conversation which occurred in the movie. Then, the researcher makes the transcription conventions for the conversations.

\section{f. Data Analysis}

Data analysis consists of conversation transcription analysis. Along with the data collection, the researcher transcribes all the polite conversations that contain slang produced by the subjects of the study. They are all characters in the movie Tuesday with Morrie. The processes of data analysis include identifying the slang used in the conversation, in what condition when the characters use the slang, the reason why the characters use the slang, and what reaction to the other characters they are talking to by seeing the sense and tone of the next dialog.

\section{RESULTS AND DISCUSSION}

To understand the conversation, it is better to describe the characteristics of the characters involve in the conversations. For the first conversation chosen, the main speakers of this conversation are Morrie and Mitch. Morrie was a professor in the university where Mitch studied. Morrie and Mitch had close relationship as a professor and a student. It has been years since the last time Mitch saw Morrie. This is their first conversation after they have not seeing each other for years. The first conversation was chosen because it can give the atmosphere of politeness and awkwardness. As the result of findings, when using slang, the athmosphere of politeness and awkwardness can be reduced.

Mitch : It's Mitch. -Mitch Albom?-I called-I-I spoke to your wife. = Morrie : $\uparrow I$ don't get a hug after 16 years?

\section{((Laughing))}

Morrie $\quad: \downarrow$ My old buddy, you came to see me at last. Let's eat.

Mitch : ((entering the kitchen)) Well, I see you still like to eat as much as ever. (2.3)

Morrie : Oh, boy, dig in, huh? Help yourself.--Come on. Make yourself comfortable.

((starting eating))

Mitch : Okay. Looks great. EhmWell, you look great.Really. Really. The same.

Connie : ((Connie comes into room bringing phone)) Morrie? Excuse me. Can you talk?

Morrie : No. Get a name if you could, Connie, because I'm with my buddy now, huh? I spend half the day on the telephone. Now that I'm dying, people are taking more of an interest in me.

Mitch : Ah, big celebrity now. How's that feel being a big TV 
star?-I mean, you know, you were always interesting, --but, uh=

Morrie : I thought so. (2.7)

Mitch : This-This one class-Do you remember this, Morrie? -Um, you didn't say anything. You remember that? You just stared at us. Hmm-We all trooped in with our notebooks ready waiting for you to start casting pearls, and nothing. Five minutes go by. Ten minutes. We started panicking. "Why-why isn't the guy saying anything?" Finally, after like-I think it was 20 minutes of that - and we really can't take it anymore, you say, very quietly.=

Morrie : "What's happening here?"

Mitch : Exactly right. "What's happening here?" That's exactly what you said. You were making a point about silence. $=$

Morrie : What is it about silence that makes people uneasy, huh?

Mitch : Right.=

Morrie : $\leftarrow$ Why do people only feel comfortable when they're filling the air with words? Hmm?

Mitch : ((Chuckles))

Morrie : Should I tell you what it's like?-Dying? That's another subject that makes people uncomfortable. We'll get to it later. You know, right now I gotta go to the commode. Are you up to, uh, giving me a hand?

Mitch : Um-sure.

Morrie : Well, now wait a minute. I better get Connie. It takes an expert. -Connie, uh-

Mitch : Ehm-

Morrie : You know, dying is just one thing to be sad about. Living unhappily, that's another matter. See ya in a minute. $=$

Mitch : Okay.

From the face expression Mitch shown us in the movie and the dialog he said, we know that Mitch was so clumsy and awkward when starting his conversation with Morrie. However, Morrie made the situation became closer by addressing Mitch as his buddy. "Buddy" is a slang which means a very close friend. So, the first person who use slang in this conversation is Morrie who are older than Mitch, which also means Morrie has more power than Mitch in the term of power in conversation. However, Morrie want to reduce the distance between them in the conversation. It is appropriate with the criteria of politeness for American which proposed by Ogawa and Gudykunst (2000). In other word, one way to reduce the distance between the speaker and hearer in conversation is by using slang.

Morrie used another slang when seeing Mitch's hesitation when entering the kitchen. His hesitation is proven by the long paused that Mitch made after entering the kitchen and talking his first line responding to Morrie's invitation. "Oh, Boy. Dig in, huh? Help yourself" is used by Morrie to respond to Mitch's hesitation. He used different addressee in here. At the beginning he addressed Mitch as his buddy, but in here he addressed Mitch as "boy". "Boy" in here is a slang which does not mean $a$ boy (according to oxford dictionary $a$ boy is a male child or young child). Mitch is a mature man, not a young child. Because it is a slang, we cannot define the word boy as what it is stated in the dictionary. It has different meaning. This is one characteristic of slang that cannot easily find its definition in the standard dictionary or it can have different meaning from what it's stated in the standard dictionary.

When Morrie said Dig in! Help Yourself, he has filled one maxim of politeness maxims. It is generosity maxim where offering someone in something. To 
fill this maxim, Morrie used this slang. The purpose of using this slang is to reduce Mitch's hesitation, and in responding to this Mitch did what Morrie asked him to do without hesitation. From this first conversation chosen, we can see that slang can be used to begin the conversation between two people who used to be close but they have been separated for a long time, so when they met again the feeling of awkwardness fills the atmosphere. So, the use of slang can be a part of politeness. As it is stated before that politeness in America emphasizes on the intimacy for equality. The use of slang can facilitate that need of politeness for American.

In the middle of the conversation, when they have felt easier to each other, the use of slang is reduced, but before Morrie ended the conversation, he used slang once more. The expression 'gotta go' in 'I gotta go to commode' is slang used by Morrie to excuse himself in the middle of conversation. It can be politeness in making excuse, but he use slang to make it like a humor because he said it in the middle of talking about a serious topic. Moreover, he also added 'Are you up to, uh, giving me hand?' to make as if his incapability like nothing serious. The response made by Mitch is can be considered as polite response. Even if Morrie use slang, Mitch still response it politely. Again, as the politeness in making a moment leavetaking, Morrie used 'See ya' to Mitch. When we read this transcript of first conversation chosen, we can see it clearly that most of slang was made by Morrie to make himself closer to Mitch, but Mitch was still hesitate to make himself closer to Morrie. The close relationship from this two characters was still not created since the slang was only used by one speaker. However, the power of slang used in conversation that made by Morrie will show its effect in second conversation chosen.

This second conversation takes place a few hours after the first conversation. From this condition, we can assume that Mitch had been easy in talking to Morrie, and the awkwardness in Mitch had been disappeared.

Morrie : Are you happy in Detroit?

Mitch : Yeah. Best town to be in for a sportswriter. Football, basketball, baseball, hockey, you name it.

Morrie : Are you giving to your community?

Mitch : --they're nuts for sports. You know, that's what I give 'em every day in my column.

Morrie : Are you at peace with yourself?

Mitch : I-I can't complain.

Morrie : Uh-huh. What happened to the music? Wasn't that your passion, to be a great pianist?

Mitch : Yeah. Yeah, I gave it a shot, then I grew up.

Morrie : You grew up, huh? -Married with kids?

Mitch : Uh, no.

Morrie : Haven't found anybody to share your heart with, huh?

Mitch : No. Yes, I have. Definitely.

Morrie : Oh. Not enough to get married?

Mitch : Uh, no. Well, y-yes. I mean, you know, someday. But, uh, just when we're both ready.

Morrie : When you're both ready? Has she got a name?

Mitch : Janine.

Morrie : Janine? That's a very beautiful name. So, Janine shares this "when we're both ready" thing with you?

Mitch : No. ((Chuckles))

Morrie : Uh-huh. ((Laughs)) I can see, Mitch, that we're gonna have a great deal to talk about. $=$

Mitch : What are you writing?

Morrie : One more question.

Mitch : Yeah?

Morrie : You know anything about this disease that I've got here? This Lou Gehrig's disease? It melts ya like a candle, you 
know? In my case, from the bottom up. [Straining] My leg-went first. Hands will be next — and eventually it'll get the whole body. But you know what I dread? Someday soon somebody's gonna have to wipe my ass for me. But-I'm a lucky man.

$\begin{array}{ll}\text { Mitch } & \text { You're lucky? } \\ \text { Morrie } & \text { : Yeah. I've still got time to } \\ & \text { learn - time to say good-bye } \\ & \text { to the people I love.... and time } \\ & \text { to teach my final course. }\end{array}$

Mitch : About dying?

Morrie : $\uparrow$ Not about dying! About living! $\downarrow$ When you know how to die, you know how to live.

The disappearance of Mitch' hesitation and awkwardness was proven by his slang used in his dialogs. When Mitch told Morrie about his job and what he felt about it, he use some slang. You name it, nuts, and I gave it a shot are slang used by Mitch in this conversation. When these slangs are used by Mitch, the atmosphere of closeness and solidarity appeared. Morrie responded seriously to Mitch's story, but then when the conversation became more intense and tended to build negative atmosphere, Morrie use slang when asking about Mitch's girlsfriend. 'Has she got a name?' is a question that equivalent with 'what is her name?'. Morrie also used gonna instead of going to.

Those are conversation that happened between to people who used to be close and they once again try themselves to speak as close as possible. They once again want to build their solidarity and close relationship by using slang sometimes. However, how about the conversation between two people who are not close? This next conversation will show us about the use of slang in the conversation between Charlotte (Morrie's wife) and Mitch.

Mitch $\quad:$ Oh, hey, Mrs. Schwartz.
Charlotte : Oh, please. Call me Charlotte, Mitch. Did he ever stop talking?

Mitch : [Chuckles] No. I was afraid I was gonna tire him out.

Charlotte : Oh, he never gets tired if he's got friends to talk to. I'm so glad you came back. You were one of his favorites.

Mitch : You going back to work?

Charlotte : Just for a couple of hours. I hope you'll come again.

Morrie : Charlotte, wasn't that a great funeral today, huh? What a turnout.! ((Laughing))

Mitch : How does he do it? How does he stay so cheerful all the time?

Charlotte : Well, sometimes the nights are difficult for him. They really are.

Morrie : Charlotte.

Charlotte : Coming, dear.

From the conversation we can find the politeness in addressing people. When Mitch called Charlotte as Mrs. Schwartz, she asked Micth to call her with her first name. Mitch responded to this invitation by including slang in his next dialog. However, because of Charlotte's next line did not show the same closeness as Morrie did, Mitch no longer used slang in his next lines. The intimacy between Charlotte and Morrie was shown from the line between Morrie and Charlotte. When Morrie called Charlotte, he used slang in his dialog to show his feeling about the living funeral. The slang turnout, which means amazing based on Dictionary of American Slang by Kipfer and Chapman (2007), was received a good response by Charlotte. So from this conversation we can conclude that the use of slang is affected by the relationship between the speaker and hearer. When the speaker and hearer have no close relationship or they do not want to make themselves closer, the rarely or even not use slang. 
In the next conversation, when the relationship between Mitch and Morrie became closer, they even do not hesitate to use various addressees for each other that can be understood by themselves, so why it is so called slang.

Mitch : $\uparrow$ Ta-da! Food man. Hey, Connie.

Connie : Hey.

Morrie : $\uparrow$ Is that Mitch? $\downarrow$ Must be Tuesday.

Mitch : It's Mitch.

Morrie : How ya doin', Coach? I hope you haven't eaten already,

Mitch : 'cause I got some very good stuff here.

Morrie : Ah, what do you got?
Mitch $\quad:$ I got-some hummus.
Morrie $\quad$ Ahhh.
Mitch $\quad:$ I got pita bread, nice and
warm. $\quad$ Yeah, good.
Morrie $\quad$ I got apple cobbler. And I
Mitch $\quad$ got-I got that.
Morrie : Huh. $\uparrow$ Tongue!
Mitch : $\uparrow$ Ugh.
Morrie : $\downarrow$ You remembered.
Mitch : Oh, you don’t forget
somebody eating tongue. No, no.

When Mitch came to Morrie's house, he addressed himself as a foodman. According to Dictionary of American Slang (2007), foodman means a person who prepare food for someone to eat. One stuff that he brought is called hummus is a kind of food that named by people from certain community and for the first it was only understood by that community. The setting of the conversation is considered as full of humour, lively, interesting and showing personality of each character. Those are the power that created by the use of slang.

Once again, the relationship between the speaker and hearer determines how slang is perceived as positive or negative. We can say that when slang used by wrong person to wrong person, it will be something negative even if the intension is for politeness. It is because this politeness do not fill tact maxim. Let's take the next conversation as the example. The next conversation was taken place in a music studio where Mitch's girlfriend worked as a backup singer. In the conversation Mitch talked to a man in studio who he was not close enough, but the man use slang when talking to Mitch. Moreover, a man in a studio is a black American who perhaps Mitch perceived him as outside group member of his community.

Studio Man: O-Oh, yeah. Come on in, baby. Let's hear it back. Oh, hey, Mitch Man, I didn't see you.

Mitch : Hey.

Studio Man: So, what do you think?

Mitch : Oh, I couldn't hear it. I was outside.

Studio Man: No, no, no. I mean, about her going solo. No more backup. She didn't tell you we're gonna lay down some tracks?

Mitch : Get outta here.

Studio Man: Oh, yeah, man. She's got the voice. I mean, all she needs is the "want to. " Very nice, baby. Let's hear playback.

When the man in the studio used slang 'gonna lay down', which means will record, Mitch responded it negatively. Even if he responded it using slang, but his expression shown his dislike to what the man said. Mitch asked the man to go out using 'get outta here'. So, tenor dimension play an important role in deciding of using slang in conversation.

The field also can play important role in deciding of using slang. From this last conversation, we can see that the use of slang is reduced because the setting of the conversation is too serious and there is no way to make humour in that serious situation. This conversation was once again taken in Morrie's house when the condition of Morrie's health is bad.

Mitch : So, who wins? 
Morrie : Love. Love always wins. You don't believe that?

Mitch : I don't know. Maybe I don't. I mean, have you looked at the news lately? Love's not exactly racking up the gold medals out there.

Morrie : Maybe the game isn't over yet. Mitch : ((turn off the tape recorder))

Morrie : What are we-- We're through?

Mitch : Coach, can I talk to you for a second as a friend?

Morrie : That's the way we always talk. Now, why did you stop the tape?

Mitch : Well, because this is, uh...Uh, I need a little help here. Um, I bought a ring for Janine-an engagement ring.

Morrie : Congratulations! Does this mean I finally get to meet her? [Coughs]

Mitch : Well, um-Look, I'm ready to make the plunge. I really am. I'm talkin' marriage, family, the whole nine-Everything I've been putting off up to this point, basically. But, umOkay, I take her way too much for granted. I always have. I know that.And, believe me, I know what a selfish jerk I can be, especially with my time. But, um-You know, it's just what you said. It's about this fear that I have about not just giving love but receiving it. And, uh-And of being part of something that isn't just all about me. And, uh-You know, uh, living for somebody else and, uh...uh, learning to give and, uh--

Morrie : She didn't like the ring?

Mitch : Oh, I never even got to give it to her.

Morrie : But you love each other?

Mitch : Yes, we do, a lot. Uh-huh. So, if love always wins, what the heck is the matter with us?
[Chuckles] I could use a little-little wisdom here.

Morrie : Maybe my wisdom isn't what you need. Start that thing again. This is our last thesis together. We got to get it right. We don't have a lot of time.

In this conversation, Mitch only used slang once, that is when he told Morrie what he thought about himself. He addressed himself as a jerk. His purpose of this slang expression is that to show his guilty about something. He brought the dialog to show his personality to share his feeling with a person he was close. It changes the style from the formal conversation that he has before with Morrie to an informal one. However, because of this conversation became more and more serious, Morrie responded it with serious manners. As the conclusion, when the field expected as to act seriously, we should follow the expectation by not using slang.

\section{IMPLICATIONS TO ELT}

Teachers can teach slang in the classroom, or teacher can encourage students to learn slang on their own; however, teachers should guide the students when learning slang to direct them to polite conversation. From the research we found that, slang can be used in polite conversation when the purpose of using slang is to build solidarity between the speaker and hearer. Obviously, slang can be found in movies. Movies are an extremely rich source for slang. The film scripts can be used to enhance the learning experience in the foreign language classroom, as well as films with and without subtitles. The popular movies can be analyzed for their slang value and serve as discussion points in the classroom.

One movie that gives use example of using slang in polite conversation is Tuesdays with Morrie. This movie can be an aid for teachers to show students the use 
of slang in polite conversation. They do not need to be worry that slang is not appropriate to be taught in the classroom; instead, it can help the students to be aware of American daily life communication. Also, it can contribute to students' understanding toward language and culture.

The main goal of EFL teachers who want to encourage students to learn slang is that students can use slang in their own polite conversation. The knowledge about how to using slang can help the students to prepare themselves when meet the situation where they have to use this kind of language to get closer to their American friends or colleagues.

In the classroom, the teachers can play a movie that contains slang in polite conversation. Then the teachers' can ask the students to analyze the appropriate condition when we use slang and how to use it properly. Teachers can give students' the point where slang is used and give a hint to the students about the appropriate used of it. After the students can analyze the slang used, they can be asked to make a conversation using that slang or asked to do role playing games. This strategies of teaching slang, can give the students an authentic material if it uses the concept of communicative approach.

\section{CONCLUSION}

Slang can be used in polite conversation because slang is not only about vulgarity and taboo words. However, the user has to determine the three dimensions of communicative event before deciding using slang. The first one is about field dimension. The speaker must consider the setting of the conversation take place. If the setting of the conversation is serious, slang should not be used or the use of slang should be reduced. However, someone can use slang in serious condition if he or she wants to create humour inside the serious topic, if that is possible. One purpose of using slang is to build solidarity, closeness, and intimacy, so if there is no intention from both hearer and speaker to build those kinds of relationship, the speaker should avoid using slang because one power of using slang is to create in-group identity and kill the gap between speaker and hearer. When we consider about tenor dimension, we will be careful in using slang if we see that the person we are talking to have no intention to be closer to us or the person who perceive us as an outsider. If we still use slang for them, they will have negative response toward us even if we just want to be polite. So, in using slang we have to consider the person who we are talking to. Moreover, for mode dimension, slang can be use in any medium of communication as long as it is in informal situation.

The power of slang is not only useful when we are in conversation, but also for teaching and learning practices. Slang has real world application in today classroom because it is authentic and real. Slang can be a motivating tool, providing color, humor and intimacy where there was none before. So, teachers can use slang for teaching language and culture using interesting strategy. For example, playing movies in the classroom and ask them to analyze the slang used in the conversation and give them a hint why and how we use that.

\section{REFERENCES}

Anderson, L., \& Trudgill, P. 1990. Bad

Language. Cambridge: Basil Blackwell.

Brown,P., \& Levinson, S. 1987.

Politeness. Cambridge:

Cambridge University Press.

Burke, D. 1998. Without Slang and Idioms, Students are in the Dark.

Retrieved from:

http://ingles.ing.uchile.cl.

Finegan, E. 2004. Language: Its Structure and Use, $4^{\text {th }} E d$. Boston:

Wadsworth.

Hayakawa, S.I. 1941. Language in Action. New York: Hardcourt Brace and Co. 
Homuth, K.J., \& Piippo, A. 2011, October. Slang in the ESL Classroom. Paper presented at Michigan Teachers of English to Speakers of Other Languages Conference, Kalamazoo, Michigan. Retrieved from: http//www. emich.edu

Huang, Y. 2008. Politeness Principle in Cross-Culture Communication. English Language Teaching, 1(1).

Janney, R. W., \& Arndt, H. 1992 . Intracultural tact versus intercultural tact. In R. J. Watts, S. Ide, \& K. Ehlich (Eds.), Politeness in language: Studies in its history, theory and practice. Berlin: Mouton de Gruyter.

Kipfer, B.A., \& Chapman, R.L. 2007. Dictionary of American Slang. New York: Collins.

Leech, G. 1983. Principles of Pragmatics. New York: Longman.

Mazer, J. P. 2006. Cool communication in the classroom: Instructor use of positive slang and its effects on student motivation, affective learning, and perceptions of teacher credibility. Unpublished master's thesis, Illinois State University, Normal, Ill.

Mazer, J.P., \& Hunt, S.K. 2008. The Effects of Instructor Use of Positive and Negative Slang on Student Motivation, Affective Learning, and Classroom Climate. Communication Research Reports, 25(1), pp. 4445.
O’Grady, W., \& Archibald, J. 2004. Contemporary Linguistic Analysis: an Introduction. Toronto: Pearson Education Canada.

Ogawa, N., \& Gudykunst, W.B. 2000. Politeness Rules in Japan and United States. Intercultural Communication Studies, 9(1). pp 47-69.

Okabe, R. 1990. Unwillingness to discard tradition: Politeness. In G. Furuta (Ed.), Keywords in intercultural communication (pp. 132-3). Tokyo: Yuhikaku.

Rothwell, J. D. 1971. Verbal obscenity: Time for second thoughts.Western Speech, 35, 231-242

Stockwell, P. 2007. Sociolinguistics: A Resource Bookfor Students, $2^{\text {nd }}$ Edition. New York: Routledge.

Ting-Toomey, S. 1994. Face and facework: An introduction. In S. Ting-Toomey (Ed.), The challenge of facework (pp. 114). Albany: State University of New York Press.

Yule, G. 1996. The Study of Language. Cambridge: Cambridge University Press.

Zhou, M. Y. Q. 2005. A McMAster Undergraduate Study of the Social Origins and Implications of Slang and Gendered Language. The McMaster Journal of Communication, 2(6) pp. 52-74. 